\title{
Ragam Kata Sapaan Kekerabatan Minangkabau di Keluarga Inti Berdasarkan Matrilineal pada Remaja Minang
}

\author{
Syifa Fadhilah Gusman ${ }^{1}$, Fidela Arminda ${ }^{2}$, Wulan Hafizah ${ }^{3}$, Yana Tasya Noveri ${ }^{4}$, Fauziyyah Wardah Tuljannah ${ }^{5}$
} ${ }^{1,2,3,4,5}$ Fakultas Psikologi dan Kesehatan, Jurusan Psikologi, Universitas Negeri Padang

syifafadhi1ah62@gmai1.com

\begin{abstract}
Minangkabau is a regional language where it is used as the main language by indigenous people in Minangkabau. In minangkabau language the word greeting many undergo changes, especially the word greeting used by teenagers. In addition, the word greeting that already exists is not used anymore by teenagers today. The purpose of the research to be carried out by researchers is, as follows, to find out and describe what are the variety of greeting words used by Minang teenagers to their matrilineal nuclear family, to find out whether the use of greeting words in Minangkabau language begins to fade in Minang teenagers, to find out if minang teenagers still want to apply minangkabau language words in everyday life. The study involved 101 participants, which has been in accordance with the criteria of minang people, namely aged 15-24 years who are male and female. This criterion is prepared to obtain information related to the use of various words of matrilineal kinship in Minangkabau. Researchers used the open-ended-quotionnaire method. The analysis techniques in this study consist of open coding and selective coding. The results of the study can be concluded that, adolescent minang in using the word Minangkabau greeting based on matrilineal kinship undergoes many changes at this time. In addition, most of the subjects studied want to apply the word Minangkabau greeting in everyday life and in the future.
\end{abstract}

Keywords: Minangkabau Language, Kata Sapaan, Matrilineal, Social Relations, Minang Youth.

\begin{abstract}
Abstrak
Bahasa Minangkabau adalah bahasa daerah dimana pemakaiannya sebagai bahasa utama oleh masyarakat asli di Minangkabau. Dalam bahasa Minangkabau kata sapaan banyak mengalami perubahan terutama kata sapaan dipergunakan oleh remaja. Selain itu kata sapaan yang sudah ada cendrung tidak digunakan lagi oleh remaja saat ini. Tujuan dari penelitian yang akan dilaksanakan oleh peneliti adalah, sebagai berikut, untuk mengetahui dan mendeskripsikan apa saja ragam kata sapaan yang digunakan oleh remaja Minang kepada keluarga inti matrilinealnya, untuk mengetahui apakah pemakaian kata sapaan dalam bahasa Minangkabau mulai memudar pada remaja Minang, untuk mengetahui apakah remaja minang masih ingin menerapkan kata saapaan bahasa minangkabau di kehidupan sehari-harinya. Pada penelitian ini melibatkan 101 partisipan, yang telah sesuai dengan kriteria orang minang yaitu berusia 15-24 tahun yang berjenis kelamin laki-laki dan juga perempuan. Kriteria ini disusun untuk memperoleh informasi terkait penggunaan ragam kata sapaan kekerabatan matrilineal di Minangkabau. Peneliti menggunakan metode open-ended-quotionnaire. Teknik analisis pada penelitian ini terdiri dari open coding dan selective coding. Hasil penelitian dapat disimpulkan bahwa, remaja minang dalam menggunakan kata sapaan Minangkabau berdasarkan kekerabatan matrilineal mengalami banyak perubahan pada saat ini. Selain itu sebagian besar subjek yang diteliti ingin menerapkan kata sapaan Minangkabau dikehidupan sehari-hari dan kedepannya.
\end{abstract}

Kata kunci: Bahasa Minangkabau, Kata Sapaan, Matrilineal, Relasi Sosial, Remaja Minang.

(C) 2021 PSY165 Journal

\section{Pendahuluan}

Manusia ialah makhluk hidup yang berbudaya dan memiliki aktifitas tidak terbatas [1]. Sebagai makhluk sosial setiap individu perlu, adanya kehadiran individu lain dalam melangsungkan kehidupan [2]. Dimana manusia pasti membutuhkan sebuah sarana agar dapat berinteraksi dengan lingkungan atau orang lain. Sarana yang paling efektif dalam menjalin hubungan dengan orang lain yaitu dengan menggunakan bahasa.

Bahasa perannya sangat penting bagi kehidupan manusia, fungsi utama bahasa yaitu sebagai alat komunikasi antara manusia satu dengan lainnya [3]. Menurut De Saussure bahwa bahasa merupakan salah satu lembaga kemasyarakatan, yang sama dengan lembaga kemasyarakatan lain [4].
Pemakaian bahasa sebagai dampak sosial sangat dipengaruhi oleh beberapa faktor. Diantaranya pendidikan, tingkat ekonomi, jenis kelamin, turut andil dalam pemakaian bahasa. Selain itu faktor situasi juga mempengaruhi seperti siapa pembicara, siapa pendengar, kapan, dan dimana bahasa digunakan juga sebagai salah satu faktor untuk menentukan pemakaian kata atau kalimat yang digunakan.

Contohnya seperti perkawinan, perwarisan harta pusaka dan lain sebagainya. Menurut Keraf tentang alat komunikasi diantara masyarakat merupakan simbol bunyi yang dihasilkan oleh alat ucap seseorang adalah pengertian dari bahasa [5]. Bahasa juga berhubungan erat dengan kebudayaan, karena bahasa merupakan bagian dari kebudayaan yang harus dijaga dan di pertahankan. Bahasa tersebut dapat berupa 
bahasa nasional maupun bahasa daerah. Salah satu bahasa daerah yang ada dan berkembang di Indonesia adalah bahasa Minangkabau [6].

Bahasa Minangkabau adalah bahasa daerah dimana pemakaiannya sebagai bahasa utama oleh masyarakat asli di Minangkabau [7]. Selain sebagai bahasa utama, bahasa Minangkabau ini memiliki fungsi, yang pertama alat yang digunakan untuk menghubungkan keluarga serta masyarakat pada saat berkomunikasi secara lisan, yang kedua bahasa juga merupakan lambang kebanggaan di kebudayaan di daerah tersebut, yang ketiga bahasa juga merupakan identitas dari Sumatera Barat serta suku bangsa di Indonesia [6]. Bahasa berdasarkan pengunaannya melahirkan ragam kata sapaan sebagai pernyataan pentingnya sapaan dalam suatu hubungan komunikasi antara penyapa dan apa yang disapa menuru Kartomiharjo [8].

Menurut Seraj dalam mewujudkan komunikasi yang ideal seorang penyapa harus menggunakan bentuk kata yang sesuai dalam berkomunikasi agar orang lain yang disapa [9], paham maksud dan tujuan dari individu yang menyapa. Salah satu bentuk komunikasi dan berelasi ini adalah sapaan. Menurut Chaer tentang bentuk sapaan ialah ungkapan untuk menyapa, menegur, atau memanggil orang yang diajak bicara [10]. Dalam bermasyarakat sapa menyapa akan terjadi bila seseorang berkomunikasi dengan orang lain. Menurut Harimurti mengatakan bahwa sapaan digunakan oleh seseorang dalam berinteraksi dan berkomunikasi dengan orang lain [11]. Kata sapaan ialah morfem, kata, atau frase yang dilakukan dalam pembicaraan yang bermacam-macam menurut sifat hubungan antara pembicara untuk saling merujuk [12]. Menurut Chaer terbagi atas dua macam kata sapaan yang pertama kata sapaan nama diri dan sapaan nama kekerabatan [11]. Penggunaan kata sapaan nama diri di pergunakan kepada yang pertama orang tua lakilaki, yang kedua orang tua perempuan dan yang ketiga saudara perempuan ataupun laki-laki yang lebih tua dan yang terakhir saudara laki-laki atau perempuan yang lebih muda [13]. Menurut Samarin istilah kekerabatan yaitu menyapa orang yang terikat dengan dirinya karena ada hubungan keturunan atau seperkawinan [11].

Seperti digunakan kepada anggota kelompok sedarah (berkerabat) contohnya kata ayah, abang, dan mertua. Kata sapaan kekerabatan dibagi menjadi 2 macam yaitu (1) kekerabatan pertalian langsung; (2) kekerabatan pertalian tidak langsung. Kata atau ungkapan dipengaruhi penggunaannya berdasarkan ciri kedewasaan yang mengikatnya [14]. Ragam kata sapaan ini mencakup penggunaannya dengan memperhatikan (1) ragam keformalan (2) ragam agak formal (3) ragam akrab. Menurut Brown dan Gilman mengungkapkan ada 2 macam hubungan atau relasi antara pembicara dan lawan bicara yaitu hubungan kekuatan dan hubungan solidaritas. Penggunaannya menunjukkan hubungan perbedaan dalam umur, kekuatan fisik, jenis kelamin dan status. Contoh penggunaan sapaan yang akrab ditandai dengan nama saja atau nama diri. Sedangkan suasana formal atau tidak akrab menggunkan titel pangkat atau jabatan, lalu diikuti dengan nama misalnya Bapak Profesor Doktor Sutono dan lainnya.

Dalam bahasa Minangkabau kata sapaan banyak mengalami perubahan terutama kata sapaan dipergunakan oleh remaja. Selain itu kata sapaan yang sudah ada cendrung tidak digunakan lagi oleh remaja saat ini. Kata sapaan dan bahasa daerah perlu mendapatkan perhatian khusus, karena pada zaman sekarang begitu banyak hal yang dapat mempengaruhi perkembangan kata sapaan dan bahasa daerah [6]. Perkembangan bahasa minang pada masyarakat Sumbar didominasi dengan penggunaan bahasa indonesia di kehidupan sehari-hari terutama di kotakota. Hal ini dilihat dari kata sapaan yang digunakan antara keluarga maupun antar masyarakat dalam hubungan kekerabatan sudah mulai pudar [15]. Seperti dalam bahasa minang adik laki-laki ibu seharusnya disapa dengan mamak, tetapi pada zaman sekarang kebanyakan mamak di sapa dengan oom. Contoh lain seperti adik perempuan ayah seharusnya disapa dengan etek tetapi kenyataannya sekarang etek di panggil dengan tante. Itulah bentuk dari penerapan kata sapaan bahasa minang yang sudah mulai hilang.

\section{Metodologi Penelitian}

\subsection{Partisipan}

Pada penelitian ini melibatkan 101 partisipan, yang telah sesuai dengan kriteria orang minang yaitu berusia 15-24 tahun yang berjenis kelamin laki-laki dan juga perempuan. Kriteria ini disusun untuk memperoleh informasi terkait penggunaan ragam kata sapaan kekerabatan matrilineal di Minangkabau.

\subsection{Desain}

Peneliti menggunakan metode open-endedquotionnaire. Suwanto, 2009 open-endedquoationnaire adalah model yang menyajikan suatu permasalahan dengan solusi yang beragam dan pemecahan masalah dengan berbagai cara [16]. Kuesioner terbuka atau open-ended-quotionnaire adalah survey atau poling opini publik yang mana pertanyaannya memungkinakan jawaban tidak di tentukan dan jawaban responden menggunakan katakatanya sendiri [17].

\subsection{Prosedur}

Penelitian yang dilakukan ini berawal dari pembuatan kuesioner dimana untuk mendapatkan partisipan yang sesuai dengan target yaitu membutuhkan waktu kurang lebih 2 minggu. Peneliti mengambil data dengan Google Form [8]. Tujuan dari pembuatan kuesioner ini untuk mengetahui apa saja kata sapaan yang digunakan pada sistem matrilineal di 
Minangkabau dan penerapan kata sapaan dikehidupan sehari-hari. Pertanyaan yang disusun adalah sebagai berikut:

i. "Kata sapaan apa yang saudara gunakan untuk anggota keluarga berikut ini:
a. Ibu kandung
b. Kakak perempuan ibu
c. Kakak laki-laki ibu
d. Adik perempuan ibu
e. Adik laki-laki ibu
f. Ibu kandung dari ibu
g. Ayah kandung dari ibu
h. Kakak laki-laki kandung
i. Adik laki-laki kandung
j. Kakak perempuan kandung
k. Adik perempuan kandung

ii. "Apakah saudara masih ingin menerapkan kata sapaan Minag dalam kehidupan sehari-hari?"
a. "Jika ya, apa alasannya?"
b. "Jika tidak, apa alasannya?"

Dalam penelitian ini enumerator adalah peneliti yang terdiri atas lima orang yang merupakan mahasiswa Psikologi Universitas Negeri Padang semester 6 . Enumerator yang dilibatkan ini yaitu mahasiswa yang telah lulus matakuliah Penulisan Karya Ilmiah dan juga matakuliah Penelitian Kualitatif, dan juga matakuliah yang sedang ditempuh saat ini diiringi dengan penelitian ini yaitu psikologi Indigenous. Beberapa kalimat yang tidak dipahami oleh partisipan diubah agar dapat dipahami dengan jelas

\subsection{Teknik Analisis}

Teknik analisis pada penelitian ini terdiri dari open coding dan selective coding, yaitu: (1) mengimput data kueisioner dari Google Form ke Ms. Excel; (2) mengurutkan respon dari partisipan sesuai dengan kemiripan kata; (3) melakukan pengkodingan berdasarkan jawaban responden; (4) mengelompokkan hasil dari pengkodingan yang telah diurutkan; (5) melakukan peninjauan terhadap pengkodingan dengan kesesuaian jawaban.

\section{Hasil dan Pembahasan}

3.1. Kata sapaan kekerabatan yang digunakan remaja Minangkabau (matrilineal)

Kata sapaan menurut garis keturunan ibu ialah kata sapaan yang digunakan untuk menyapa orang-orang yang mamiliki hubungan darah (kandung). Berdasarkan hasil analisis Tabel 1 hingga Tabel 11, bentuk kata sapaan yang digunakan oleh remaja Minang berdasarkan garis keturunan ibu beraneka ragam. Kata sapaan ibu kandung terdapat 11 ragam, kata sapaan kakak perempuan ibu terdapat 20 ragam, kata sapaan kakak laki-laki ibu terdapat 15 ragam, kata sapaan adik laki-laki ibu terdapat 12 ragam, kata sapaan adik perempuan ibu terdapat 12 ragam, kata sapaan ibu kandung dari ibu terdapat 10 ragam, kata sapaan ayah kandung dari ibu terdapat 21 ragam, kata sapaan kakak laki-laki kandung terdapat 5 ragam, kata sapaan adik laki-laki kandung terdapat 6 ragam, kata sapaan kakak perempuan kandung terdapat 6 ragam dan kata sapaan adik perempuan kandung terdapat 4 ragam. Kata sapaan yang digunakan Remaja Minang Kabau (Matrilinieal) disajkan pada Tabel 1 sampai dengan Tabel 11.

Tabel 1. Ibu Kandung

\begin{tabular}{cc}
\hline Acuan & $\mathrm{n}$ \\
\hline Abun & 1 \\
Ama & 11 \\
Amak & 6 \\
Bunda & 7 \\
Ibu & 23 \\
Ibuk & 1 \\
Mam & 1 \\
Mama & 45 \\
Mami & 3 \\
Umak & 1 \\
Umi & 2 \\
\hline
\end{tabular}

Tabel 2. Kakak Perempuan Ibu

\begin{tabular}{lc}
\hline Acuan Kata Sapaan & $\mathrm{n}$ \\
\hline Tidak ada & 29 \\
Aci & 1 \\
Ama & 3 \\
Amai & 1 \\
Amak & 2 \\
Ante & 5 \\
Anti & 1 \\
Bulok & 1 \\
Bunda & 6 \\
Bundo & 1 \\
Etah & 1 \\
Etek & 4 \\
Ibu & 6 \\
Mak gadang & 1 \\
Mak tuo & 17 \\
Makdang & 2 \\
Mama & 6 \\
Mami & 3 \\
Tante & 7 \\
Uni & 4 \\
\hline
\end{tabular}

Tabel 3. Adik laki-laki Kandung

\begin{tabular}{cc}
\hline Acuan Kata Sapaan & $\mathrm{n}$ \\
\hline Tidak ada & 41 \\
Panggil nama & 25 \\
Adek & 9 \\
Adiak & 6 \\
Adik & 14 \\
Brother & 1 \\
Dedek & 5 \\
\hline Tabel 4. Adik Laki-laki Ibu \\
\hline Acuan Kata Sapaan & $\mathrm{n}$ \\
\hline Tidak ada & 29 \\
Abi & 1 \\
Aciak & 7 \\
Mak etek & 8 \\
Mak itam & 1 \\
Mak dang & 4 \\
Mak ngah & 3 \\
Mamak & 10 \\
Metek & 2 \\
Om & 27 \\
Ucu & 8 \\
Uwan & 1 \\
\hline
\end{tabular}


Tabel 5. Kakak Laki-laki Ibu

\begin{tabular}{lc}
\hline Acuan Kata Sapaan & $\mathrm{n}$ \\
\hline Tidak ada & 23 \\
Acik & 1 \\
Adang & 1 \\
Angah & 3 \\
Angku & 1 \\
Ayah & \\
Mak dang & 12 \\
Mak etek & 7 \\
Mak utiah & 1 \\
Mak uwo & 2 \\
Makngah & 1 \\
Mamak & 25 \\
Om & 20 \\
Pak long & 1 \\
Uda & 1 \\
Uwan & 1 \\
\hline
\end{tabular}

Tabel 6. Adik Perempuan Ibu

\begin{tabular}{cc}
\hline Acuan Kata Sapaan & $\mathrm{n}$ \\
\hline Tidak ada & 26 \\
Aciak & 1 \\
Ama & 2 \\
Amai & 1 \\
Ami & 2 \\
Ante & 8 \\
Bunda & 6 \\
Etek & 21 \\
Ibu & 8 \\
Incim & 2 \\
Mama & 2 \\
Tante & 20 \\
Teteh & 2 \\
\hline
\end{tabular}

Tabel 7. Ibu Kandung dari Ibu

\begin{tabular}{lc}
\hline Acuan Kata Sapaan & $\mathrm{n}$ \\
\hline Tidak ada & 1 \\
Amak & 12 \\
Enek & 7 \\
Mak gaek & 6 \\
Ibu & 2 \\
Iniak & 4 \\
Mak uwo & 7 \\
Mama & 2 \\
Nenek & 46 \\
Oma & 10 \\
Umi & 4 \\
\hline
\end{tabular}

Tabel 8. Kakak Perempuan Kandung

\begin{tabular}{ll}
\hline Acuan Kata Sapaan & $\mathrm{n}$ \\
\hline Tidak ada & 45 \\
Panggil nama & 3 \\
Akak & 2 \\
Kakak & 29 \\
Neng & 2 \\
Onang & 3 \\
Uni & 17
\end{tabular}

Tabel 9. Kakak laki-laki Kandung

\begin{tabular}{cl}
\hline Acuan Kata Sapaan & $\mathrm{n}$ \\
\hline Tidak ada & 39 \\
Panggil nama & 6 \\
Abang & 36 \\
Brother & 1 \\
Uda & 16 \\
Sali & 3 \\
\hline
\end{tabular}

Tabel 10. Ayah Kandung dari Ibu

\begin{tabular}{ll}
\hline Acuan Kata Sapaan & $\mathrm{n}$ \\
\hline Tidak ada & 4 \\
Abak & 14 \\
Agek & 1 \\
Akek & 1 \\
Angku & 10 \\
Antan & 1 \\
Atuk & 6 \\
Ayah gaek & 4 \\
Ayek & 1 \\
Buya & 1 \\
Datuak & 3 \\
Enek & 2 \\
Gaek & 6 \\
Inyiak & 4 \\
Kakek & 33 \\
Mak inang & 1 \\
Ompung & 2 \\
Opa & 7 \\
Pak gek & 1 \\
Ungku & 1 \\
Uwan & 1 \\
Uwo & 3 \\
\hline
\end{tabular}

Tabel 11. Adik Perempuan Kandung

\begin{tabular}{ll}
\hline Acuan Kata Sapaan & $\mathrm{n}$ \\
\hline Tidak ada & 51 \\
Panggil nama & 21 \\
Adek & 13 \\
Adiak & 4 \\
Adik & 12 \\
\hline
\end{tabular}

\subsection{Penggunaan Kata Sapaan Kekerabata} Minangkabau Pada Remaja Minang

Pada Tabel 12 berdasarkan (Sumardi,2019) terdapat ragam kata sapaan bahasa Minangkabau diantaranya menurut kekerabatan matrilineal berdasarkan identifikasi ragam kata sapaan bahasa Minangkabau tersebut peneliti mendapatkan data penelitian berupa hasil kuisoner yang dibagikan kepada remaja Minang dengan rentang umur 15-24 tahun. Hasil jawaban dari partisipan menunjukkan bahwa ragam kata sapaan Minangkabau yang sesuai (Favorable) menunjukkan jumlah yang lebih sedikit dari pada tidak sesuai (Unfavaroble). Rata-rata favorable berjumlah $22,41 \%$ dan unfavorable dengan rata-rata berjumlah $51,66 \%$. Sedangkan Neutral rata-ratanya berjumlah $25,92 \%$.

Keterangan Tabel 12 adalah sebagai berikut:

Favorable $=$ sesuai dengan kata sapaan kekerabatan matrilineal Minangkabau.

Unfavorable = tidak sesuai dengan kata sapaan kekerabatan matrilineal Minangkabau.

Neutral $=$ tidak memiliki kerabat matrilineal Minangkabau.

3.3. Alasan penerapan kata sapaan kekerabatab Minangkabau di kehidupan sehari-hari pada remaja Minang

Pada Tabel 13 (lihat Tabel 13) menunjukkan alasan remaja Minang dalam menerapkan keinginan mereka menggunakan kata sapaan kekerabatan matrilinel Minangkabau dalam kehidupan sehari-harinya. Jika remaja Minangkabau menjawab "Ya" menunjukkan 
bahwa mereka masih ingin menerapkan kata sapaan Minang, sedangkan bagi yang menjawab "Tidak" menunjukkan bahwa mereka tidak ingin menerapkan kata sapaan Minang di kehidupan sehari-harimya walaupun ia adalah orang Minang. Hasil penelitian

Tabel 12. Penggunaan Kata Sapaan Kekerabatan Minangkabau pada Remaja Minang

\begin{tabular}{|c|c|c|c|c|c|}
\hline \multirow{2}{*}{ No } & \multirow{2}{*}{$\begin{array}{l}\text { Hubungan } \\
\text { matrilineal }\end{array}$} & \multirow{2}{*}{ Ragam sapaan minangkabau } & \multicolumn{3}{|c|}{ Jawaban partisipan } \\
\hline & & & Favorable & Jnfavorable & Neutral \\
\hline 1 & Ibu kandung & Amak, andeh, biai, bundo, ibu, iyeik, mandeh, umak, uwaik & 32 & 69 & 0 \\
\hline 2 & Kakak perempuan ibu & mak angah, mak tuo & 17 & 55 & 29 \\
\hline 3 & Kakak laki-laki ibu & Adang, angku, datuak, tuan & 2 & 76 & 23 \\
\hline 4 & Adik laki-laki ibu & Ucu, mamak & 18 & 54 & 29 \\
\hline 5 & Adik perempuan ibu & Aciak, angah, etek, uncu, teta, teti & 22 & 53 & 26 \\
\hline 6 & Ibu kandung dari ibu & Ayek, anduang, mak gaek, nenek, niniak, inek, iniak, uci & 56 & 44 & 1 \\
\hline 7 & Ayah kandung dari ibu & Ayah, angku, datuak, gaek, inyiak & 21 & 76 & 4 \\
\hline 8 & Kakak laki-laki kandung & Abang, ajo, uda, udo, uwan, uwo & 52 & 10 & 39 \\
\hline 9 & Adik laki-laki kandung & Adiak, waang & 6 & 54 & 41 \\
\hline 10 & Kakak perempuan kandung & Aciak, akak, one, uniang, uni, uwo & 19 & 37 & 45 \\
\hline 11 & Adik perempuan kandung & Adiak, gadih, gau, kau, upiak & 4 & 46 & 51 \\
\hline \multicolumn{3}{|c|}{ Jumlah } & 249 & 574 & 288 \\
\hline \multicolumn{3}{|c|}{ Rata-rata } & $22,41 \%$ & $51,66 \%$ & $25,92 \%$ \\
\hline
\end{tabular}

Tabel 13. Alasan Penerapan Kata Sapaan Kekerabatan Matrilineal Minangkabau Dikehidupan Sehari-Hari pada Remaja Minang

\begin{tabular}{|c|c|c|}
\hline Alasan penerapan kata sapaan Minangkabau & $\mathrm{n}$ & Presentase \\
\hline Ya & & \\
\hline $\begin{array}{l}\text { Alasan Ciri khas } \\
\text { Ciri khas sebagai orang Minang }\end{array}$ & 4 & $3,96 \%$ \\
\hline $\begin{array}{l}\text { Alasan Kebiasaan } \\
\text { Sudah terbiasa menggunakan kata sapaan } \\
\text { Sudah diajari dari kecil oleh orangtua }\end{array}$ & $\begin{array}{l}15 \\
10\end{array}$ & $\begin{array}{l}14,85 \% \\
9,90 \%\end{array}$ \\
\hline $\begin{array}{l}\text { Alasan Kesopanan } \\
\text { Bahasa Minang lebih sopan } \\
\text { Menghargai seseorang }\end{array}$ & $\begin{array}{l}2 \\
2\end{array}$ & $\begin{array}{l}1,98 \% \\
1,98 \%\end{array}$ \\
\hline $\begin{array}{l}\text { Alasan Melestarikan } \\
\text { Membudidayakan adat Minangkabau } \\
\text { Merupakan tradisi Minangkabau } \\
\text { Mempertahankan bahasa Minang } \\
\text { Menjaga warisan Minangkabau } \\
\end{array}$ & $\begin{array}{c}21 \\
2 \\
4 \\
23 \\
\end{array}$ & $\begin{array}{c}20,79 \% \\
1,98 \% \\
3,60 \% \\
22,77 \% \\
\end{array}$ \\
\hline Jumlah & 83 & $82,17 \%$ \\
\hline Tidak & & \\
\hline $\begin{array}{l}\text { Alasan Kebiasaan } \\
\text { Sudah jarang dipakai } \\
\text { Kebiasaan menggunakan bahasa Indonesia } \\
\text { Kebiasaan ajaran orangtua dari kecil }\end{array}$ & $\begin{array}{l}1 \\
4 \\
4\end{array}$ & $\begin{array}{l}0,99 \% \\
3,96 \% \\
3,96 \%\end{array}$ \\
\hline $\begin{array}{l}\text { Alasan Kesopanan } \\
\text { Tidak enak didengar karena terlalu kuno } \\
\text { Kurang sopan karena bukan sapaan umum }\end{array}$ & $\begin{array}{l}1 \\
1\end{array}$ & $\begin{array}{l}0,99 \% \\
0,99 \%\end{array}$ \\
\hline $\begin{array}{l}\text { Alasan Melestarikan } \\
\text { Ingin membuat perubahan pada penggunaan bahasa } \\
\text { Tidak merasa perlu melestarikan bahasa Minang } \\
\text { Tidak sesuai dengan perkembangan zaman }\end{array}$ & $\begin{array}{l}2 \\
1\end{array}$ & $\begin{array}{l}1,98 \% \\
0,99 \%\end{array}$ \\
\hline Jumlah & 18 & $17,82 \%$ \\
\hline Jumlah dan rata-rata & 101 & $100 \%$ \\
\hline
\end{tabular}

Faktor pertama alasan remaja Minangkabau mempertahankan ciri khas kata sapaan Minangkabau berjumlah 4 orang $(3,96 \%)$, yaitu:

"Kalau tidak dilestarikan ciri khas kata sapaan Minang seiring berjalannya waktu akan menghilang" (S3)

"Karena kata sapaan menjadi ciri khas orang Minang"(S7)

Faktor kedua alasan remaja Minangkabau yang ingin mempertahankan kebiasaan kata sapaan Minangkabau berjumlah 25 orang (24,75\%). Pada umumnya kata sapaan di Minangkabau sudah menjadi kebiasaan yang diterapkan dari kecil oleh orangtua kepada anaknnya, diantaranya:

"Karena sudah dibiasakan menggunakan kata sapaan di Minangkabau” (S66)

"Karena dikeluarga masih erat dengan budaya Minang”(S65) 
Selain itu, alasan remaja Minangkabau yang tidak ingin mempertahankan kebiasaan kata sapaan Minangkabau berjumlah 9 orang $(8,91 \%)$, diantaranya:
"Karena bahasa Indonesia sudah dibiasakan dikehidupan sehari-hari, jadi kata sapaan Minangkabau tidak digunakan” (S80)
"Karena dikeluarga budaya Minang tidak terlalu melekat dan lebih cendrung menggunakan bahasa Indonesia dirumah"(S32)

Faktor ketiga alasan remaja Minangkabau menganggap kata sapaan Minangkabau sopan dalam berelasi berjumlah 4 orang $(3,96 \%)$, diantaranya:

"Panggilan Minang terkesan sopan dan
mewah"(S13)

"Karena kata sapaan digunakan untuk mengharai seseorang"(S12)

Selain itu remaja Minangkabau yang tidak menganggap kata sapaan Minangkabau sopan dalam berelasi berjumlah 2 orang (1,98\%), diantaranya:

"Karena terlalu kuno dan tidak enak
didengar"(S17)

"Kata sapaan di Minangkabau tidak memperngaruhi kesopanan, karena bisa menggunakkan panggilan umum saja"(S76)

Faktor keempat alasan remaja Minangkabau yang ingin melestarikan berjumlah 50 orang $(49,14 \%)$, misalnya kata sapaan di Minangkabau ingin di dilestarikan oleh remaja Minangkabau karena mencerminkan daerah, diantaranya:

"Untuk melestarikan panggilan tersebut agar tidak hilang” (S3)

"Karena kata sapaan tersebut merupakan budaya khas yang mencerminkan daerah Minangkabau" (S75)

Selain itu ada beberapa remaja yang tidak ingin melestarikan kata sapaan Minangkabau berjumlah 7 orang $(6,93 \%)$, misalnya kata sapaan sudah tidak sesuai dengan perkembangan zaman seperti sekarang ini, diantaranya:

"Hanya tetua yang masih menggunakan kata sapaan Minang, sedangkan anak-anak zaman sekarang sudah tidak menggunakannya karena tidak umum" (S93)

"Karena jarang pulang ke kampung, merasa tidak perlu untuk dilestarikan" (S72)

3.4. Perbandingan antara alasan menerapkan dan yang tidak menerpkan kata sapaan kekerabatan matrilineal Minangkabau

Pada Tabel 14, hasil data penelitian yang didapatkan oleh peneliti menunjukkan adanya perbedaan antara yang ingin menerapkan kata sapaan Minangkabau atau yang tidak ingin menerapkan kata sapaan Minangkabau. Hal ini dilihat dari 4 alasan yaitu karena ciri khas budaya Minang, kebiasaan orang Minang, kesopanan dalam berelasi dan Melestarikan kata sapaan Minangkabau. Rata-rata alasan remaja Minang menerapkan kata sapaan Minangkabau yaitu $82,17 \%$, sedangkan rata-rata alasan remaja Minang yang tidak ingin menerapkan kata sapaan Minangkabau yaitu $17,82 \%$.

Hal ini menunjukkan banyaknya remaja Minang yang ingin menerapkan kata sapaan Minangkabau di kehidupan sehari-harinya dan dimasa depan dibandingkan remaja Minang yang tidak ingin menerapkan kata sapaan Minangkabau.

Tabel 3. Perbandingan Antara Alasan Menerapkan dan yang Tidak Menerapkankata Sapaan Kekerabatan Matrilineal Minangkabau

\begin{tabular}{lcc}
\hline Alasan & Favorable $(\mathrm{n})$ & Unfavorable $(\mathrm{n})$ \\
\hline Ciri Khas & 4 & 0 \\
Kebiasaan & 25 & 9 \\
Kesopanan & 4 & 2 \\
Melestarikan & 50 & 7 \\
\hline Jumlah & 83 & 18 \\
\hline Rata-Rata & $82,17 \%$ & $17,82 \%$ \\
\hline
\end{tabular}

\section{Kesimpulan}

Berdasarkan hasil penelitian dapat disimpulkan bahwa, remaja minang dalam menggunakan kata sapaan Minangkabau berdasarkan kekerabatan matrilineal mengalami banyak perubahan pada saat ini. Terdapat 11 ragam kata sapaan kekerabatan matrilineal Minangkabau yang meliputi, ibu kandung, kakak perempuan ibu, kakak laki-laki ibu, adik perempuan ibu, adik laki-laki ibu, ibu kandung dari ibu, ayah kandung dari ibu, kakak perempuan kandung, kakak laki-laki kandung, adik perempuan kandung, dan adik laki-laki kandung. Dari 11 ragam kata sapaan ini memiliki banyak perubahan atau sudah memudar pada remaja minang. Hasil penelitian sebagian besar subjek yang diteliti ingin menerapkan kata sapaan Minangkabau dikehidupan sehari-hari dan kedepannya, hal ini karena pandangan mereka bahwa kata sapaan merupakan budaya turun temurun yang harus ada dan tidak boleh punah, juga kata sapaan Minangkabau melambangkan ciri khas tersendiri dari budaya Minangkabau dan kata sapaan Minangkabau merupakan Bahasa yang sopan dan patut untuk dipertahankan.

\section{Daftar Rujukan}

[1]. Subiyakto, B. (2019). ILMU PENGETAHUAN SOSIAL Bambang Subiyakto Pendidikan IPS FKIP Universitas Lambung Mangkurat Mutiani Pendidikan IPS FKIP Universitas Lambung Mangkurat Pendahuluan Eksistensi sebuah bangsa terwujud melalui penggalian kearifan lokal pada setiap wilayah di ne. 17(1), 137-166. https://doi.org/10.18592/khazanah.v17i1.2885

[2]. Ariyani, N. I. (2013). Strategi Adaptasi Orang Minang Terhadap Bahasa, Makanan, dan Norma Masyarakat Jawa. 
$5(17)$,

$26-37$

https://doi.org/https://doi.org/10.15294/komunitas.v5i1.2369

[3]. Devianty, R. (2017). Bahasa Sebagai Cermin Kebudayaan 24(1). https://doi.org/http://dx.doi.org/10.30829/tar.v24i2.167

[4]. Laiman Akhii, Ngudining Rahayu, C. W. (2018). Campur Kode dan Alih Kode dalam Percakapan di Lingkup Perpustakaan Universitas Bengkulu. II(1), 45-55. https://doi.org/https://doi.org/10.33369/jik.v2i1.5556

[5]. Moh. Fajrik, Akhmad Sofyan, A. D. S. (2018). Istilah-Istilah Komponen Perahu dan Struktur Pengurus Nelayan di Desa Kilensari Kecamatan Panarukan Kabupaten Situbono (Kajian Etimologi dan Semantik). 6(2), 152-158. https://doi.org/https://doi.org/10.19184/pb.v6i2.8715

[6]. Utama, F. R., \& Arief, E. (2012). Kata Sapaan dalam Bahasa Minangkabau di Kenagarian Tuik IV Koto Mudiak Batang Kapas Kabupaten Pesisir Selatan. Jurnal Pendidikan Bahasa Dan Sastra Indonesia, 1(1), 646-653. https://doi.org/https://doi.org/10.24036/1379-019883

[7]. Rahmadani B, Agustina, A. A. (2013). Perbedaan Fonetik Bahasa Minangkabau di Kenagarian Sinuruik dan Kenagarian Kajai Kecamatan Talamau Kabupaten Pasaman Barat. 1(2), 528-534. https://doi.org/https://doi.org/10.24036/1369-019883

[8]. Yulistio, D. (2016). Variasi (Ragam) Sapaan Dalam Pemakaian Bahasa (Kajian Sosiolinguistik dalam Bahasa Melayu Bengkulu) Didi Yulistio. Wacana, 14(1), 79-91. https://doi.org/https://doi.org/10.33369/jwacana.v14i1.870

[9]. Arrasyid, I., Juita, N., Studi, P., \& Indonesia, S. (2017). Penggunaan Kata Sapaan Bahasa Minangkabau di Nagari Koto Sani Kecamatan X Koto Singkarak Kabupaten Solok. 11(1). https://doi.org/https://doi.org/10.24071/sin.v11i1.929

[10]. Ketrin. (n.d.). Sapaan dalam bahasa dayak long ilu di kecamatan krayan kabupaten nunukan provinsi kalimantan utara. https://doi.org/https://doi.org/10.24071/sin.v11i1.929

[11]. Misnawati, M. (2017). Kata Sapaan Bahasa Minangkabau. Jurnal Elektronik WACANA ETNIK, 6(1), 13-19. https://doi.org/10.25077/we.v6.i1.65

[12]. Ghofur, A. (2013). Analisis Ragam Tuturan para Pelaku Pasar Kabupaten Pamekasan ( Studi Sosiolinguistik Penggunaan Variansi Sapaan ). 10(2). https://doi.org/https://doi.org/10.19105/nuansa.v10i2.171

[13]. Rusbiyantoro, W. (2011). Penggunaan kata sapaan dalam bahasa melayu kutai. 2(1), 59-76. https://doi.org/https://doi.org/10.14710/parole.v2i1\%20April. $59-76$

[14]. Putri, N. W. (2021). Fenomena Keberagaman Bahasa di Kota Bandar Lampung. https://doi.org/https://doi.org/10.20961/prasasti.v6i1.48742

[15]. Sunani, U. (2019). Interpretasi Makna Sapaan "Mas" terhadap Etnik Jawa di Makasar (Studi Komunikasi antarBudaya di Makassar). 15(2), 241-262. https://doi.org/https://doi.org/10.24239/almishbah.Vol15.Iss2.165

[16]. Sari, L. N. I., Syahputra, E., \& Asmin, A. (2015). Peningkatan Kemampuan Koneksi Matematis dan Berpikir Kreatif Siswa Melalui Pembelajaran Open Ended di SMP Muhammadiyah 03 Medan. Tabularasa, 12(1), 70-83. https://doi.org/10.24114/jt.v12i1.3224

[17]. Popping, R. (2015). Analyzing Open-ended Questions by Means of Text Analysis Procedures. BMS Bulletin of Sociological Methodology/ Bulletin de Methodologie Sociologique, 128(1), 23-39. https://doi.org/10.1177/0759106315597389 